Provided for non-commercial research and education use. Not for reproduction, distribution or commercial use.

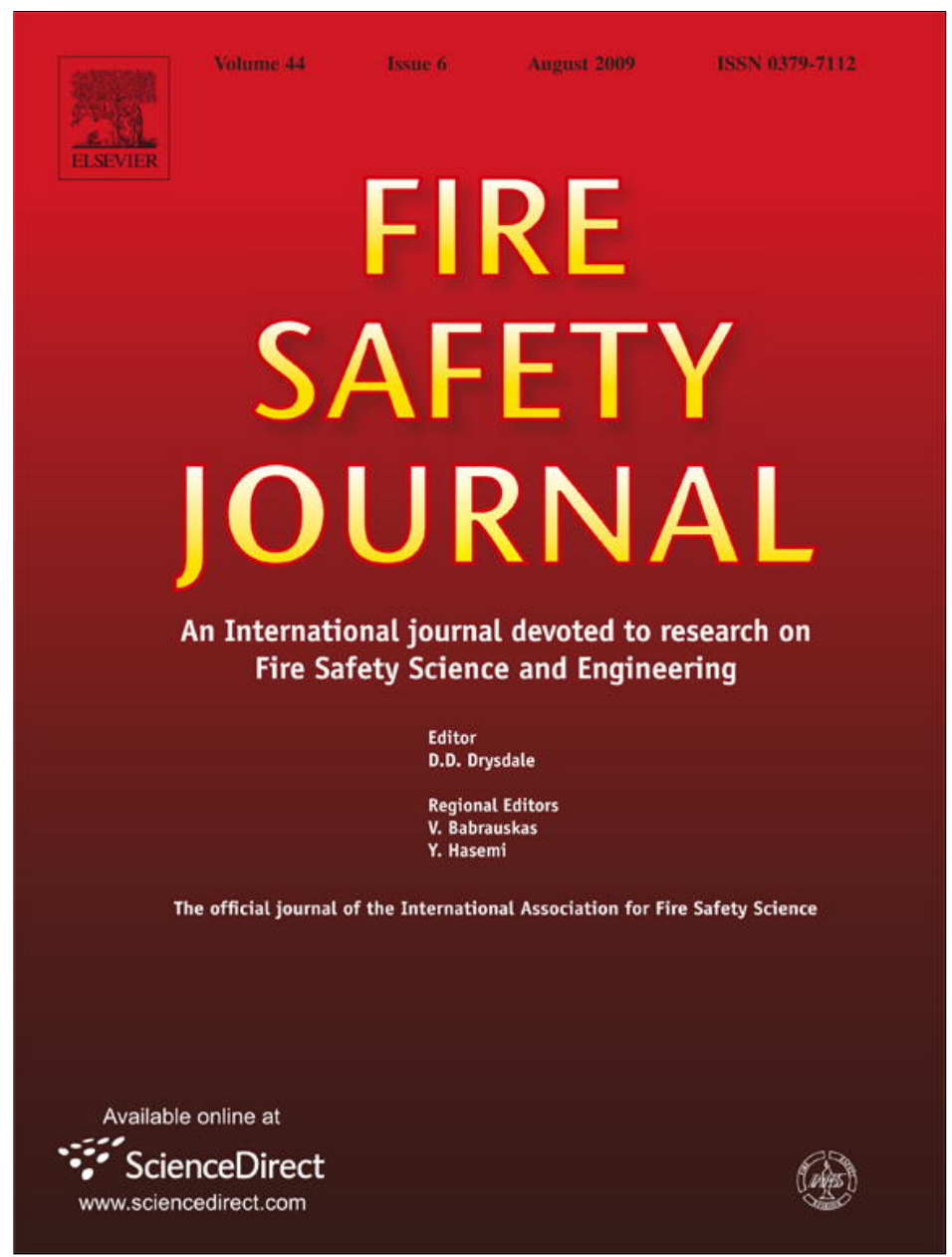

This article appeared in a journal published by Elsevier. The attached copy is furnished to the author for internal non-commercial research and education use, including for instruction at the authors institution and sharing with colleagues.

Other uses, including reproduction and distribution, or selling or licensing copies, or posting to personal, institutional or third party websites are prohibited.

In most cases authors are permitted to post their version of the article (e.g. in Word or Tex form) to their personal website or institutional repository. Authors requiring further information regarding Elsevier's archiving and manuscript policies are encouraged to visit:

http://www.elsevier.com/copyright 


\title{
Numerical modelling of timber connections under fire loading using a component model
}

\author{
Paulo B. Cachim ${ }^{\mathrm{a}, *}$, Jean-Marc Franssen ${ }^{\mathrm{b}}$ \\ a Department of Civil Engineering/LABEST, University of Aveiro, DECivil, 3810-193 Aveiro, Portugal \\ ${ }^{\mathrm{b}}$ Department ArGEnCo, University of Liege, 1 Chemin des chevreuils, B-4000 Liege 1, Belgium
}

\section{A R T I C L E I N F O}

\section{Article history:}

Received 31 July 2008

Received in revised form

25 March 2009

Accepted 27 March 2009

Available online 5 May 2009

\section{Keywords:}

Component model

Timber

Fire

Dowel

Connections

\begin{abstract}
A B S T R A C T
This paper describes a component model for dowelled timber connections under fire loading. The component model of the dowelled connection is first developed and calibrated for room temperature. The constitutive relations for dowel-timber interaction are detailed and compared with experimental results. In the fire situation, a two-step approach is used: first, three-dimensional (3D) thermal analysis of the connection is performed using a conductive model with timber properties defined in Eurocode 5 in order to calculate the temperatures in the fasteners and timber; afterwards, the mechanical analysis using a component model is carried out using mechanical properties of the steel dowel and of timber adjusted to the temperatures obtained by the thermal analyses. These properties are reduced according to Eurocode 3 and Eurocode 5, respectively. Numerical simulations are presented that allow evaluation of the model behaviour and performance. Obtained results show good agreement with available experimental data, indicating that regardless of its simplicity, the component model has the capability to accurately model timber connections under fire loading.
\end{abstract}

c) 2009 Elsevier Ltd. All rights reserved.

\section{Introduction}

Connections are key elements in structures. The knowledge of the behaviour of the connections is therefore fundamental for an adequate modelling of structures. In the case of timber connections, they are usually considered in analysis either as fully rigid or fully hinged while, in reality, their behaviour is in fact semirigid. Because the load-deformation behaviour of the connections will influence the overall stress distribution, assuming a semirigid behaviour will allow more realistic structural modelling that takes into consideration stress redistribution between elements.

For the design at room temperatures, the current design methodology of many codes, e.g. Eurocode 5 [1], is based on a plastic limit state design that allows the calculation of the ultimate load-bearing capacity of the connections. However, a simple expression that is a function only of the timber density and fastener diameter is also proposed for the load-slip characterization of the connections. This expression does not consider some effects, such as the load to grain angle or the geometry of the connection, which are fundamental for accurate modelling.

Numerical modelling of timber connections at room temperature has been performed using numerous methods. Although connections are clearly three dimensional (3D) and can be

\footnotetext{
* Corresponding author. Tel.: +351234370049; fax: +351234370094.

E-mail address: pcachim@ua.pt (P.B. Cachim).
}

modelled as such [2-5], their behaviour can also be decomposed and analysed in two separate two-dimensional (2D) approaches: one in the plane perpendicular to the dowel axis (Fig. 1, left) and one in the plane parallel to the dowel axis (Fig. 1, right). The behaviour perpendicular to the dowel is usually modelled by 2D finite element models [6-9], while the behaviour parallel to the dowel is usually modelled with beam finite elements for the dowel and springs for timber [10-16].

Under fire conditions, the modelling of timber connections has been studied less extensively. Examples of 3D finite element modelling of the thermal behaviour of timber connections under fire loading can be found in [5,17]. In [5], the mechanical analysis of the connection is also performed. To our knowledge, there has never been an application of the component model for timber connections in the fire situation.

An interesting conclusion, stated by König and Fontana [18], is that the effect of the number of fasteners for the calculation of the load ratio-time to failure curves is very small. Thus, the use of a single dowel for modelling dowel-type timber connections under fire should provide accurate results.

The goal of this paper is the development of a simple, yet accurate, component model for the behaviour of steel dowelled timber connections under fire loading. In order to reach this goal, constitutive models were implemented and finite element simulations were performed using the finite element code SAFIR [19], which is a special purpose finite element code, developed at the University of Liege for studying structures subjected to fire. 


\begin{tabular}{|c|c|c|c|}
\hline \multicolumn{2}{|c|}{ Nomenclature } & & characteristic density of timber $\left(\mathrm{kg} / \mathrm{m}^{3}\right)$ \\
\hline \multirow[t]{3}{*}{$\alpha$} & angle to the grain (when used as subscript it is & $n_{90}$ & ratio between $\eta_{0}$ and $\eta_{90}$ \\
\hline & replaced by 0 when parallel to grain and by 90 when & $p_{y, \alpha}$ & yield displacement at an angle $\alpha$ to the grain (mm) \\
\hline & perpendicular to the grain) & $p_{u, \alpha}$ & ultimate displacement at an angle $\alpha$ to the grain ( $\mathrm{mm}$ ) \\
\hline$f_{y}$ & steel yield stress $\left(\mathrm{N} / \mathrm{mm}^{2}\right)$ & $\eta_{\alpha}$ & ratio between $F_{u, \alpha}$ and $F_{y, \alpha}$ \\
\hline$P_{\alpha}$ & property at an angle $\alpha$ to the grain & $K_{1, \alpha}$ & initial stiffness at an angle $\alpha$ to the grain $\left(\mathrm{N} / \mathrm{mm}^{2}\right)$ \\
\hline$f_{h, \alpha}$ & $\begin{array}{l}\text { embedding strength at an angle } \alpha \text { to the grain } \\
\left(\mathrm{N} / \mathrm{mm}^{2}\right)\end{array}$ & $K_{2, \alpha}$ & $\begin{array}{l}\text { post-yielding stiffness at an angle } \alpha \text { to the grain } \\
\left(\mathrm{N} / \mathrm{mm}^{2}\right)\end{array}$ \\
\hline$F_{y, \alpha}$ & yield strength at an angle $\alpha$ to the grain $(\mathrm{N} / \mathrm{mm})$ & & ratio between $k_{1,0}$ and $k_{1,90}$ \\
\hline$F_{u, \alpha}$ & ultimate strength at an angle $\alpha$ to the grain $(\mathrm{N} / \mathrm{mm})$ & $K_{f c}(\theta)$ & reduction factor for strength \\
\hline$k_{90}$ & parallel/perpendicular strength ratio & $K_{E c}(\theta)$ & reduction factor for stiffness \\
\hline
\end{tabular}

\section{The component model in timber connections at room temperature}

The component model considers the connection as an assembly of individual components. Once the individual constitutive components are identified and characterized, the overall behaviour of the connection can be modelled through the socalled assembly procedures. Each component behaves in a way that is independent of the other components, of the connection layout and of the loading type. Therefore, each component can be modelled separately, with its own stiffness and strength. When the connection is loaded, the distribution of forces in the connection is determined by the relative stiffness/strength and by the position of the individual components. Application of the component model to timber connections thus requires the knowledge of the behaviour of all individual components of the timber connection. For a dowel-type connection with a single fastener, two components can be clearly identified: (i) the timber component and (ii) the steel dowel component.

\subsection{Timber component}

The behaviour of the timber component can be determined by embedding tests as prescribed for instance in EN 383 [20]. A schematic testing apparatus is shown in Fig. 2. The specimen thickness $(D)$ is limited to the range 1.5-4.0 times the dowel diameter, $d$. It can then be assumed that the vertical displacements of the infinitely stiff dowel are the same along the whole length of the dowel.

Typical force-displacement behaviour of embedding tests is shown in Fig. 3 for loads parallel and perpendicular to the grain. The interaction between the dowel and the timber can usually be represented in a simplified way by two straight lines, the intersection of which determines the onset of yielding of timber. The force-displacement relationship is dependent on the diameter of the dowel, the angle between force and grain, and the density or stiffness of timber.

The angle to the grain is a fundamental parameter for the definition of force-displacement curves because it is the one that has the highest influence on the shape of the curves. Results of tests showing force-displacement curves can be found for instance in [10,15,21-22]. When the force is applied along the grain, the ultimate strength and the initial stiffness are higher while the stiffness after yielding is smaller than when the force is perpendicular to the grain.

The ultimate load increases with the diameter of the dowel but not proportionally. The displacement that corresponds to the yielding increases proportionally with the dowel diameter and, as

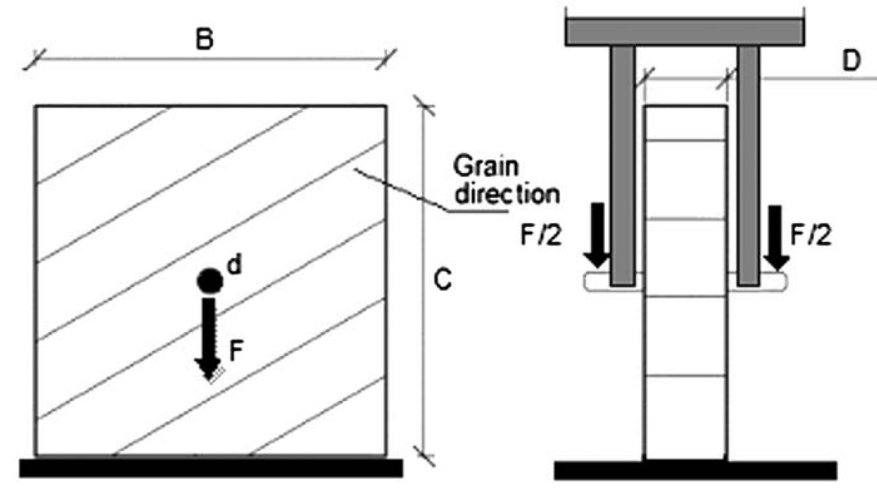

Fig. 2. Test principle according to EN 383. a

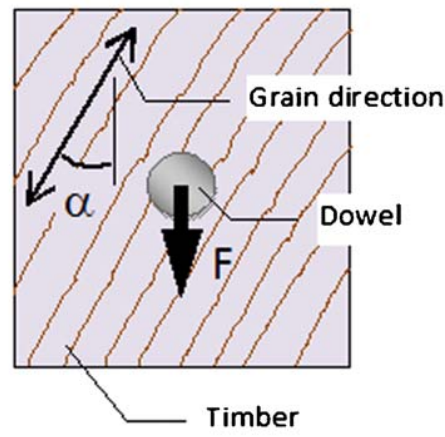

Perpendicular to the dowel axis b

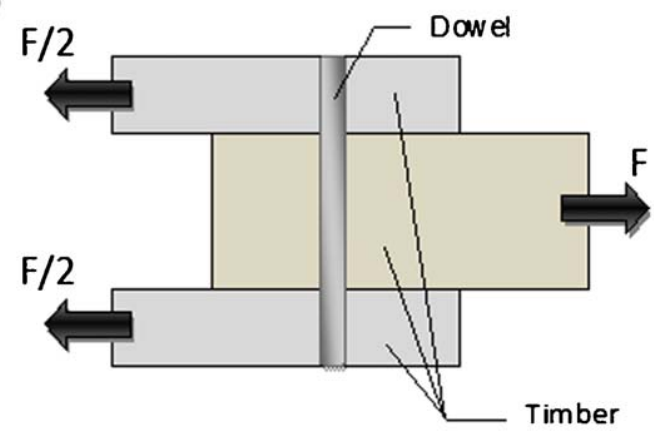

Parallel to the dowel axis

Fig. 1. Possibilities of 2D timber connection modelling. 
a consequence, the initial stiffness is practically independent of the diameter of the dowel [15]. An increase of timber density and stiffness would increase both the initial stiffness and the ultimate force.

\subsection{Dowel component}

The dowel component is represented as a beam. The materially nonlinear behaviour of the section can be captured if the section is discretized by a fibre model where the steel dowel crosssection was divided in small elements (fibres) each one with a one-dimensional stress-strain relation. An elastic-perfectly plastic stress-strain relation was considered in this work for the material model of the dowels at room temperature.

\subsection{Component model of the connection with one fastener}

With the behaviour of the components being determined, it is possible to assemble the different components into the connection model. The proposed layout is presented in Fig. 4 for the case of a fastener in double shear. A typical finite element modelling of the component model of the connection uses a series of beam elements to discretize the dowel with a spring connected at each node and representing the behaviour of the timber.

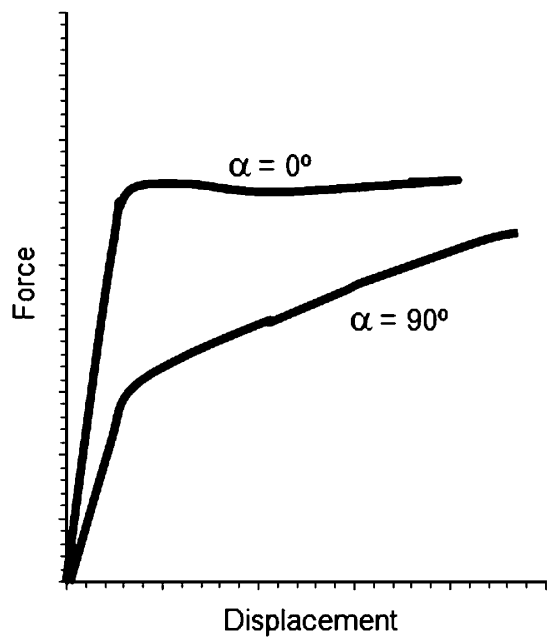

Fig. 3. Force-displacement behaviour in embedding tests.

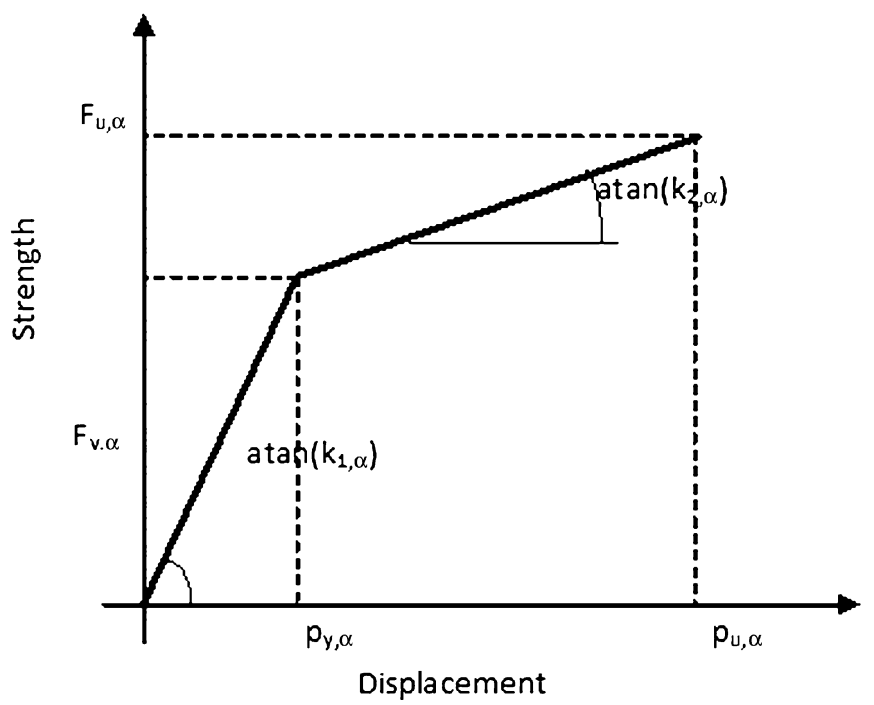

Fig. 5. Idealized force-displacement curve for dowel-timber interaction.

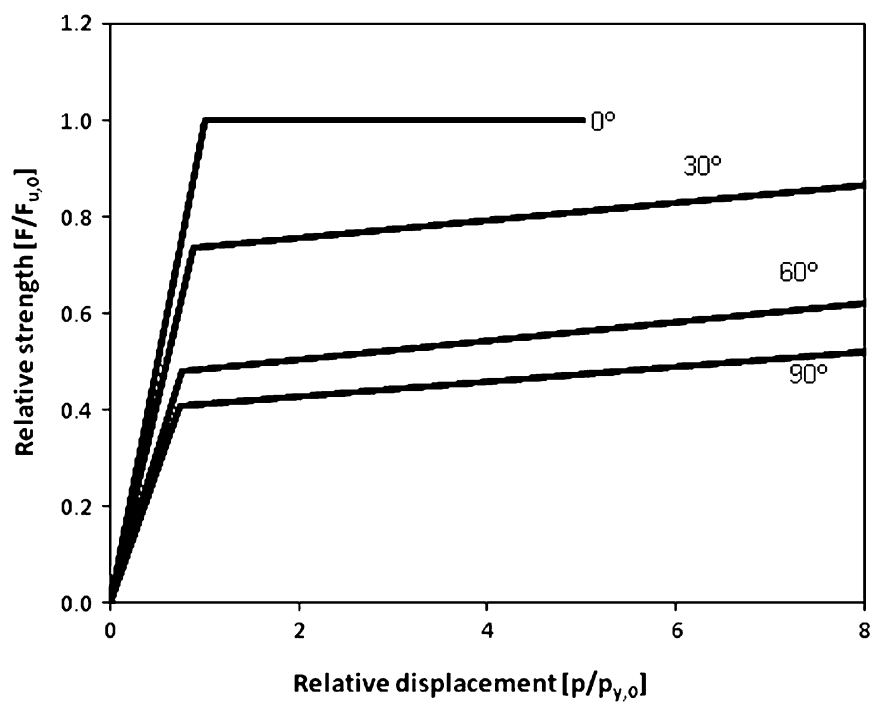

Fig. 6. Relative strength-relative displacement curves for $\alpha=0^{\circ}, 30^{\circ}, 60^{\circ}$ and $90^{\circ}$.

Force (F), displacement $(p)$
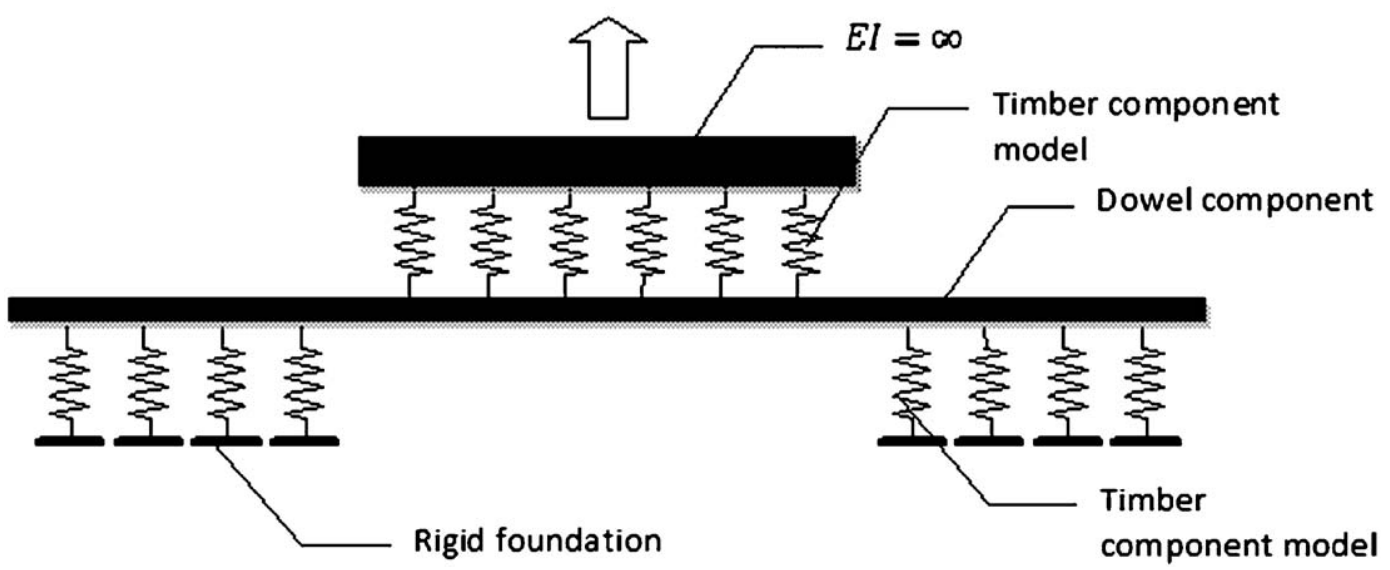

Fig. 4. Model of a single fastener connection. 
In this paper, the properties of the timber components are defined considering that these components are continuously distributed over the dowel length (modulus of subgrade reaction concept). This means that strength of the timber component, $F$, is defined from now in this work in terms of force per unit length of dowel and, consequently, stiffness units are force per unit area; embedding strength of timber, $f_{h}$, is defined in the common units of Eurocode that is force per unit area. In finite element simulations, localized springs at nodes are commonly used; in this case, the strength and stiffness properties of the timber components presented here must be multiplied by the length of influence of the springs, either the distance or half the distance between the springs.

\subsection{Determination of the parameters of the timber component at room temperature}

All parameters of the model should ideally be determined experimentally. It may however happen that the required experimental test results are not available or that, as is the case here, generic properties have to be used because the model is used for a theoretical study and not for the analysis of a particular timber species or sample.

In this section, the available formulas presented in Eurocode 5 are used, together with additional information when needed, to derive generic properties of the timber component.

The general constitutive model for the timber component is shown in Fig. 5 on which the relevant parameters are indicated. The parameters are dependent on the force to grain direction, $\alpha$. A total of four parameters are necessary to completely define the

Table 1

Summary of embedding tests.

\begin{tabular}{|c|c|c|c|c|c|c|}
\hline \multirow[t]{2}{*}{ Name } & \multirow[t]{2}{*}{ Author reference } & \multicolumn{5}{|c|}{ Geometry } \\
\hline & & $B(\mathrm{~mm})$ & $C(\mathrm{~mm})$ & $D(\mathrm{~mm})$ & $\alpha(\operatorname{deg})$ & $D(\mathrm{~mm})$ \\
\hline $\begin{array}{l}\text { E1 } \\
\text { E2 }\end{array}$ & Lam [15] & 280 & 280 & 280 & $\begin{array}{r}0 \\
90\end{array}$ & 20 \\
\hline $\begin{array}{l}\text { E3 } \\
\text { E4 } \\
\text { E5 } \\
\text { E6 }\end{array}$ & Pederson [21] & 170 & 170 & 40 & $\begin{array}{r}0 \\
30 \\
60 \\
90\end{array}$ & 12 \\
\hline
\end{tabular}

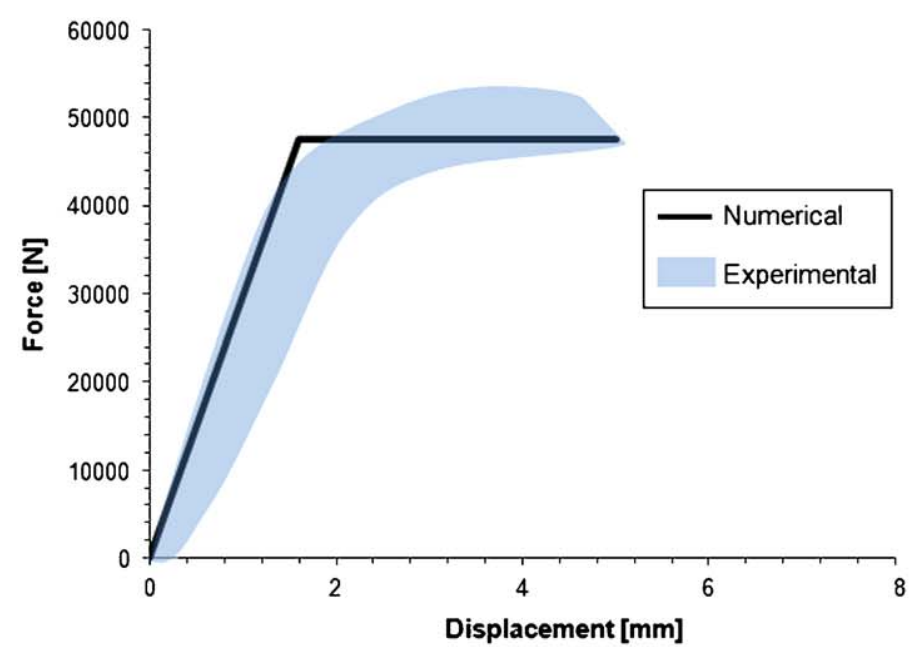

model, for each $\alpha$ value. However, by using the well-known Hankinson expression, a property value at an angle $\alpha$ to the grain can be obtained from the parallel (subscript 0 ) and perpendicular (subscript 90) to grain directions as

$P_{\alpha}=\frac{P_{0}}{\left(P_{0} / P_{90}\right) \sin ^{2} \alpha+\cos ^{2} \alpha}$,

where $P$ relates to the specified property. Consequently, eight parameters must be determined to describe the model completely.

The ultimate strength for dowels or bolt fasteners, $F_{u, \alpha}$, is given in Eurocode 5 [1] as

$F_{u, \alpha}=f_{h, \alpha} d=\frac{f_{h, 0} d}{k_{90} \sin ^{2} \alpha+\cos ^{2} \alpha}$,

where $d$ is the fastener diameter and $f_{h, \alpha}$ the embedding strength at an angle $\alpha$ to the grain, $f_{h, 0}$ the embedding strength parallel to grain and $k_{90}$ is the parallel/perpendicular embedding strength ratio $\left(f_{h, 0} / f_{h, 90}\right)$. When no experimental data are available for $f_{h, 0}$ and $f_{h, 90}, F_{u, \alpha}$ can be obtained using Eurocode 5, EC5, embedding strength for dowels expression:

$F_{u, \alpha}=\frac{F_{u, 0}}{k_{90} \sin ^{2} \alpha+\cos ^{2} \alpha}=\frac{0.082(1-0.01 d) \rho_{k} d}{k_{90} \sin ^{2} \alpha+\cos ^{2} \alpha}$,

where $d$ is in $\mathrm{mm}, \rho_{k}$ is the timber density in $\mathrm{kg} / \mathrm{m}^{3}$ and $k_{90}$ reads [1]

$k_{90}=1.35+0.015 d$.

For the other model parameters there is no information available in EC5 and, therefore, they have to be obtained by comparing the model with experimental data. The yield strength, $F_{y, \alpha}$, can be related to the ultimate strength by multiplying the latter by a factor $\eta_{\alpha}$ :

$F_{y, \alpha}=\eta_{\alpha} F_{u, \alpha}$.

Previously quoted experimental results $[15,21]$ show that $\eta_{0}=1.0$ and that $\eta_{90}$ ranges from 0.5 to 0.8 . By knowing the values $\eta_{0}$ and $\eta_{90}$ it is possible, using Eq. (5), to calculate $F_{y, 0}$ and $F_{y, 90}$. The value $F_{y, \alpha}$ can be related to $F_{u, 0}$ with help of Hankinson equation as

$F_{y, \alpha}=\frac{\eta_{0}}{\eta_{0} / \eta_{90} k_{90} \sin ^{2} \alpha+\cos ^{2} \alpha} F_{u, 0}$.

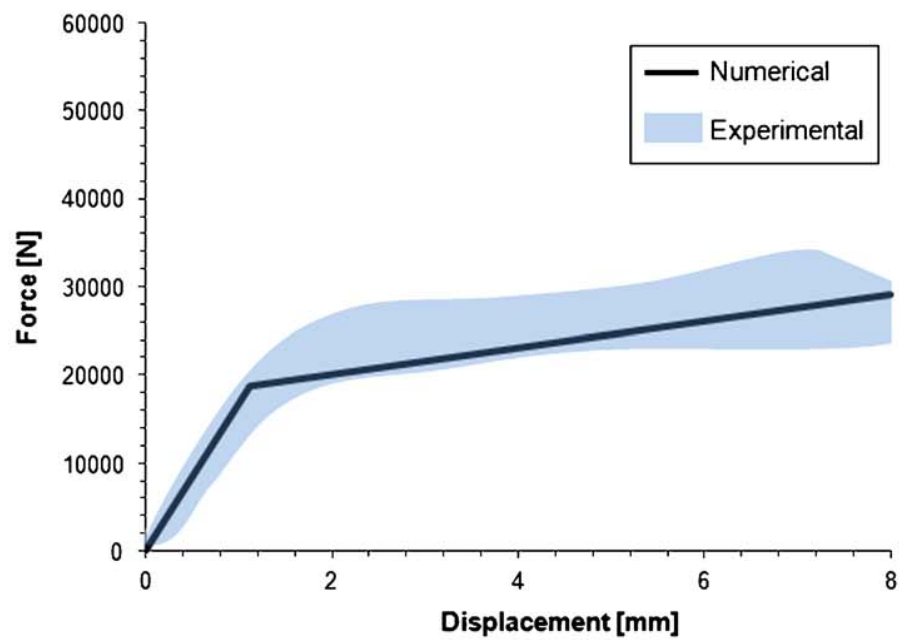

Fig. 7. Modelling of $20 \mathrm{~mm}$ dowel embedding tests (left: E1; right: E2). 
The expression for $\eta_{\alpha}$ as a function of $\eta_{0}$ and $\eta_{90}$ can finally be obtained as

$\eta_{\alpha}=\frac{F_{y, \alpha}}{F_{u, \alpha}}=\frac{k_{90} \sin ^{2} \alpha+\cos ^{2} \alpha}{n_{90} k_{90} \sin ^{2} \alpha+\cos ^{2} \alpha} \eta_{0}$,

where $n_{90}=\eta_{0} / \eta_{90}$. When experimental data are not available an average value of $\eta_{90}=0.65$ can be considered.

With the four strength parameters calculated, $F_{y, 0}, F_{y, 90}, F_{u, 0}$ and $F_{u, 90}$, it is necessary to define the initial and post-yield stiffness of the model (or the yield and ultimate displacements). The values for the yield displacement, $p_{y, \alpha}$, must be determined from available experimental results. Lam [15] stated that stiffness is independent of the dowel diameter (diameters of tested dowels ranged from 10 to $20 \mathrm{~mm}$ ). Using the results of [15,21], the displacement $p_{y, 0}$ is given by the following proposed expression, similar to the Eurocode expression for the embedding strength,

$p_{y, 0}=0.1(1-0.01 d) d(\mathrm{~mm})$.

Eq. (8) fits reasonably well with experimental results. It yields $p_{y, 0}$ equals to $0.9 \mathrm{~mm}$ for $d=10$ and $1.6 \mathrm{~mm}$ for $d=20 \mathrm{~mm}$. Using the fact that $\eta_{0}=1$, the value $k_{1,0}$ can be calculated as

$k_{1,0}=\frac{F_{y, 0}}{p_{y, 0}}=0.82 \eta_{0} \rho_{k}=0.82 \rho_{k}\left(\mathrm{~N} / \mathrm{mm}^{2}, \mathrm{~kg} / \mathrm{m}^{3}\right)$.
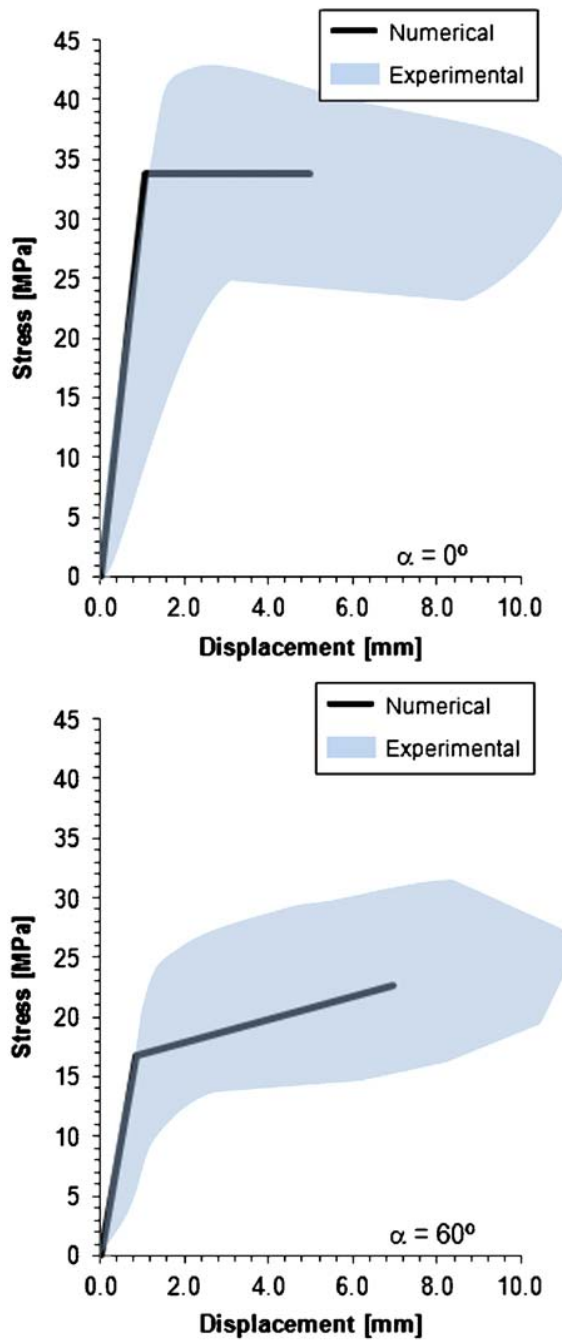

The stiffness $k_{1,90}$ can be assumed to be related to the stiffness $k_{1,0}$ by a factor $\zeta_{90}$ as

$k_{1,0}=\zeta_{90} k_{1,90}$.

Data from results of $[15,21]$ lead to $\zeta_{90}$ in the range $1.5-2.0$ and, for analysis purposes, in the absence or experimental data, can be estimated as $\zeta_{90}=1 \cdot 8$. The value $k_{1, \alpha}$ then reads

$k_{1, \alpha}=\frac{k_{1,0}}{\zeta_{90} \sin ^{2} \alpha+\cos ^{2} \alpha}$.

From Fig. 5, and using Eqs. (2), (7) and (11), the yield displacement $p_{y, \alpha}$ is given by

$p_{y, \alpha}=\frac{F_{y, \alpha}}{k_{1, \alpha}}=\frac{\zeta_{90} \sin ^{2} \alpha+\cos ^{2} \alpha}{n_{90} k_{90} \sin ^{2} \alpha+\cos ^{2} \alpha} p_{y, 0}$.

Table 2

Summary of single fastener tests.

\begin{tabular}{llllll}
\hline \multirow{2}{*}{ Name } & \multicolumn{2}{l}{ Side member } & & \multicolumn{2}{l}{ Central member } \\
\cline { 6 - 6 } \cline { 5 - 6 } & Thickness $(\mathrm{mm})$ & Grain $(\mathrm{deg})$ & & Thickness $(\mathrm{mm})$ & Grain (deg) \\
& 40 & 0 & 80 & 0 \\
S1 & 40 & 0 & 80 & 0 \\
S2 & 80 & 90 & 80 & 0 \\
S3 & 40 & 90 & 80 & 0 \\
S4 & 80 & & &
\end{tabular}
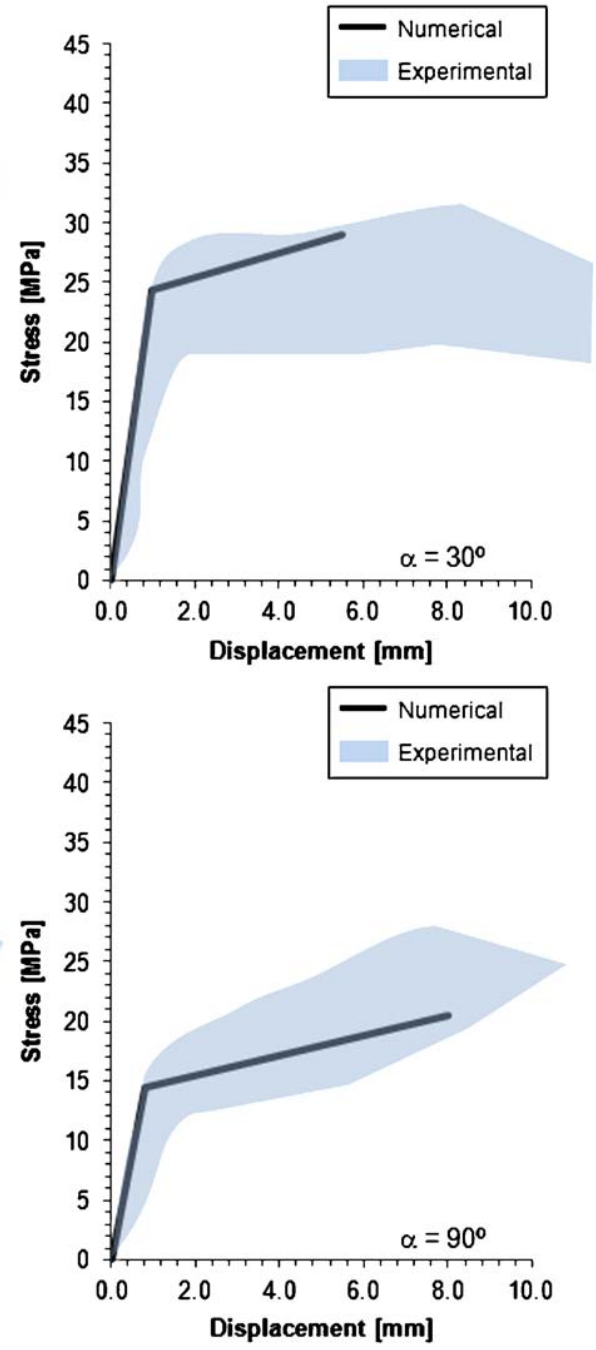

Fig. 8. Modelling of $12 \mathrm{~mm}$ dowel embedding tests E3-E6. 


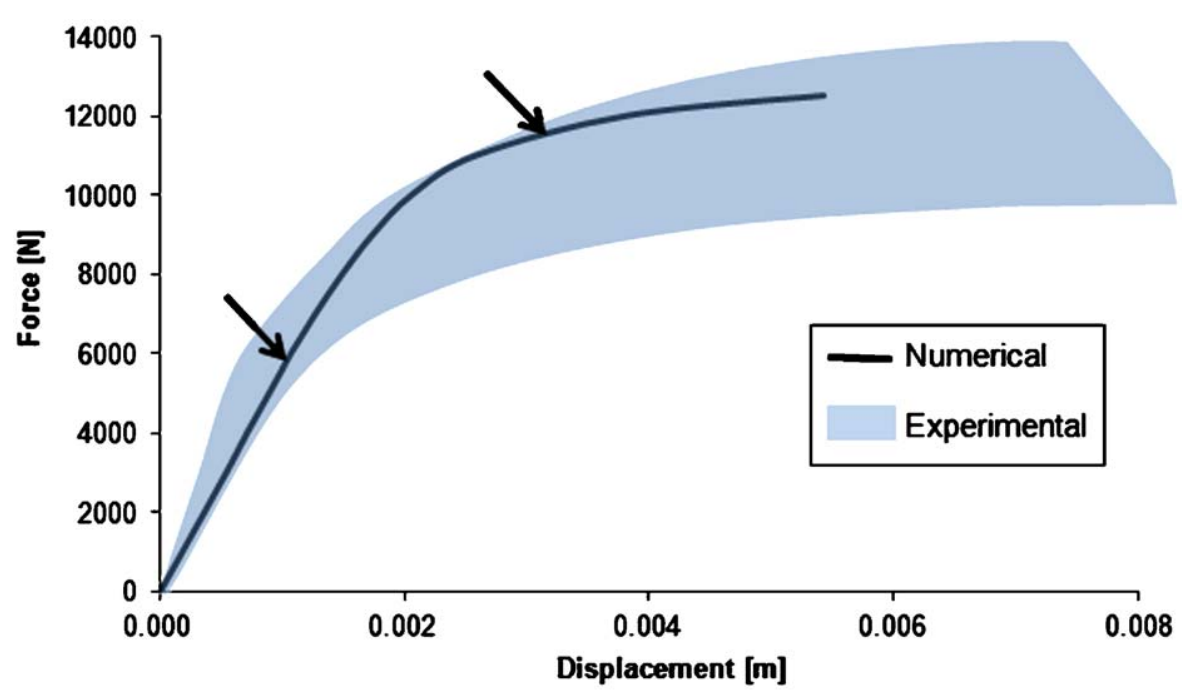

Fig. 9. Modelling of test S1.

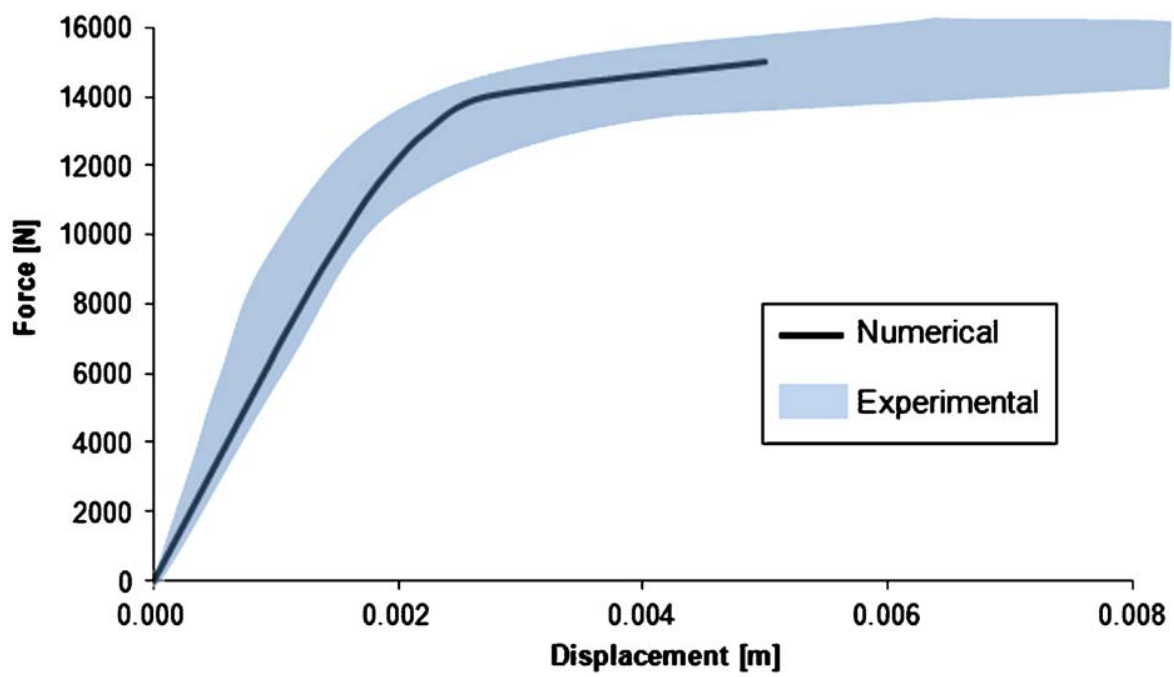

Fig. 10. Modelling of test S2.

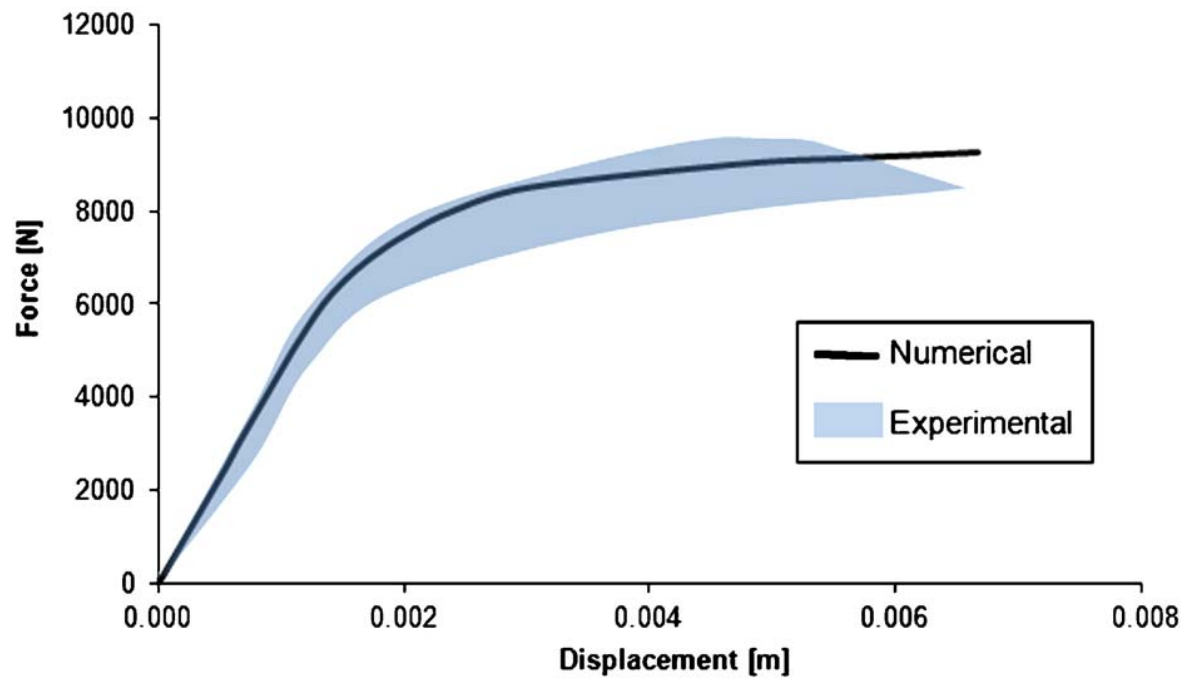

Fig. 11. Modelling of test S3. 


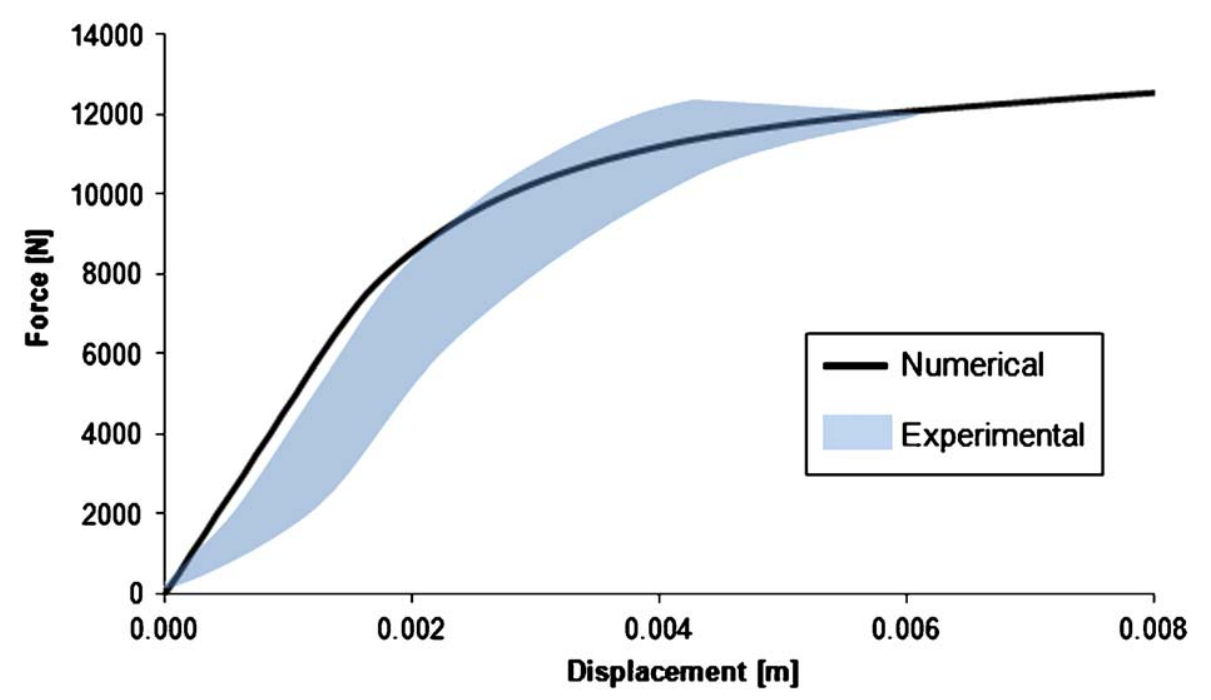

Fig. 12. Modelling of test S4.

Table 3

Summary of single fastener tests.

\begin{tabular}{lcrrl}
\hline Name & \multicolumn{2}{l}{ Failure load } & & Failure mode \\
\cline { 2 - 4 } & Model (N) & EC5 (N) & Plastic (N) & \\
\hline S1 & 12480 & 12334 & 12044 & Central hinge \\
S2 & 15000 & 14586 & 13394 & Two hinges \\
S3 & 9250 & 9776 & 9622 & Central hinge \\
S4 & 12625 & 13042 & 11980 & Two hinges \\
\hline
\end{tabular}

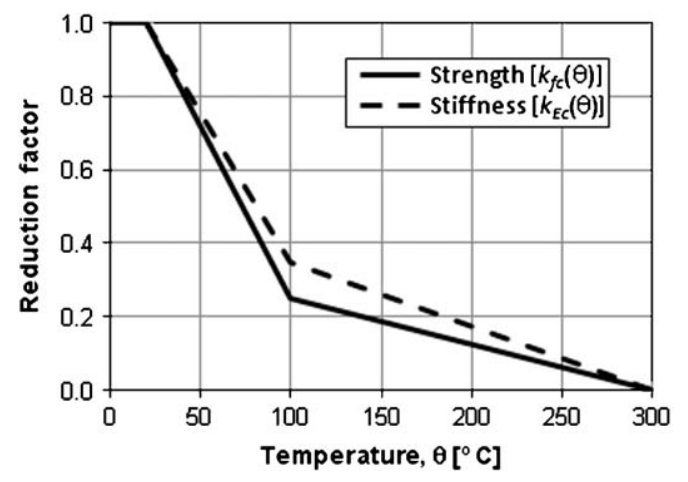

Fig. 13. Reduction factor for stiffness and strength.

The final set of parameters that must be defined are the ultimate displacements $p_{u}$. There is not, to our knowledge, reliable information for these values. In fact, the embedding strength tests performed according to EN 383 stop at an ultimate displacement of $5 \mathrm{~mm}$. However, experimental results indicate that timber continues to sustain load beyond this value, especially for loads applied perpendicular to the grain. In the absence of more consistent data, the values of $p_{u, 0}=5 \mathrm{~mm}$ and $p_{u, 90}=8 \mathrm{~mm}$ are suggested.

The value $k_{2, \alpha}$ is obtained as

$k_{2, \alpha}=\frac{F_{u, \alpha}-F_{y, \alpha}}{p_{u, \alpha}-p_{y, \alpha}}$.

Fig. 6 shows the relative strength-relative displacement curves for $\alpha=0^{\circ}, 30^{\circ}, 60^{\circ}$ and $90^{\circ}$ using the parameters $n_{90}=1.0 / 0.65$, $\zeta_{90}=1 \cdot 8, p_{u, 0}=5 \mathrm{~mm}$ and $p_{u, 90}=8 \mathrm{~mm}$.

\section{Model performance verification of the model performance at room temperature}

The constitutive relations were implemented in the software code SAFIR in order to perform numerical calculations. To assess the performance of the model at room temperature, numerical results were compared with experimental results obtained from the literature. Two types of tests were considered: embedding tests, that allow the evaluation of the generic parameters of timber component model, and single fastener tests, that allow the assessment of the component model.

\subsection{Embedding tests}

Model performance obtained with the generic properties determined as mentioned in the previous section was assessed by comparisons with results of embedding test carried out according to EN 383. The test layout is shown in Fig. 2. The test is stopped whenever the applied load, $F$, reaches its maximum or the applied displacement reaches $5 \mathrm{~mm}$. The embedding stress, $f_{h}$, is obtained as $f_{h}=F / d D$ (where $D$ is the specimen thickness, see Fig. 2). Table 1 summarises the geometry of the simulated tests as well as their reference.

Model parameters $\eta_{90}$ and $\zeta_{90}$ were considered with their default values of 0.65 and 1.8 , respectively. In Fig. 7, numerical results for E1 and E2 are compared with corresponding experimental tests. Timber density was $456 \mathrm{~kg} / \mathrm{m}^{3}$. It can be seen that calculated force-displacement curves fall within the range of experimental results. Both stiffness and strength are accurately modelled.

Fig. 8 shows the comparison of numerical and experimental results of test series E3-E6. Timber density was $470 \mathrm{~kg} / \mathrm{m}^{3}$. Again, the calculated results are in good agreement with experimental results, with the exception of ductility that was higher in the tests than considered in the model. The proposed model parameters are considered as sufficiently accurate to model the embedding behaviour of steel dowels in timber connections.

\subsection{Single fastener behaviour}

The numerical model was then compared with experimental tests on symmetrical timber to timber connection (double shear) performed by Lam [15]. In this paper, the results of the 

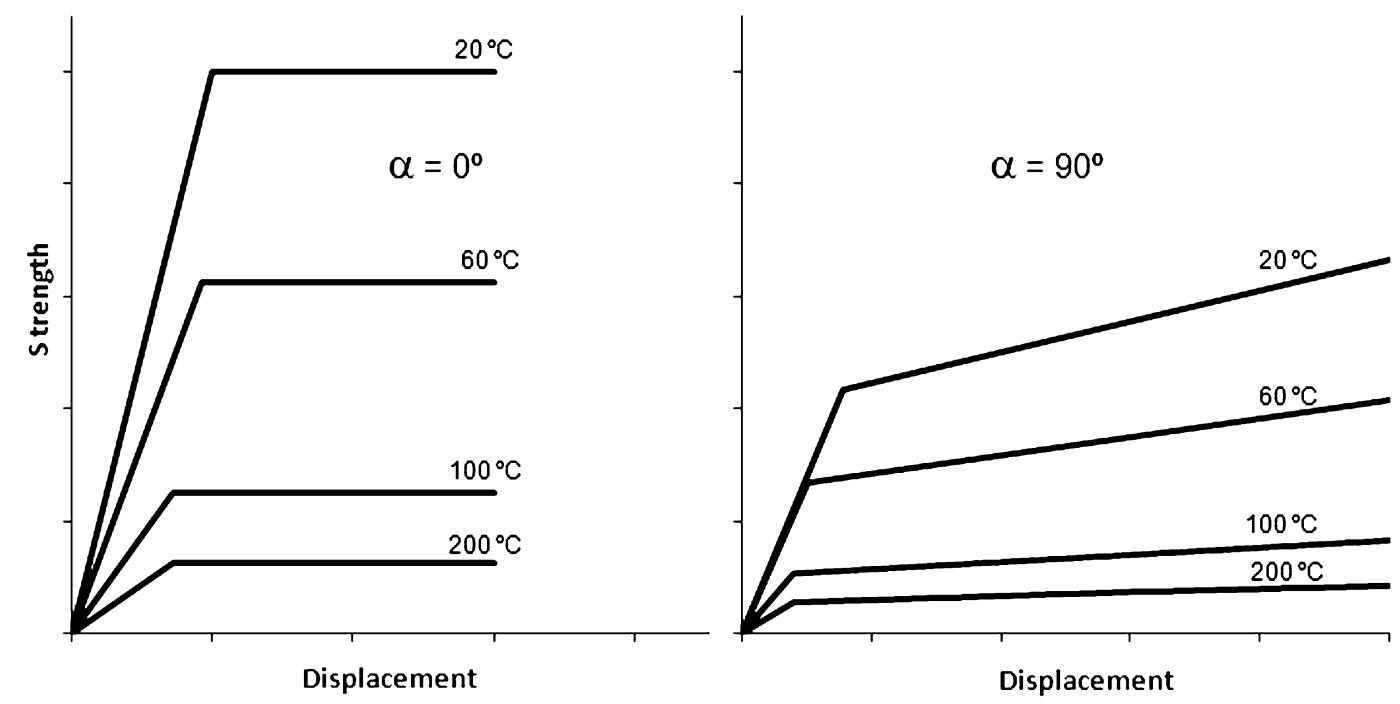

Fig. 14. Relative strength-displacement curves at selected temperatures for $\alpha=0^{\circ}$ and $90^{\circ}$.

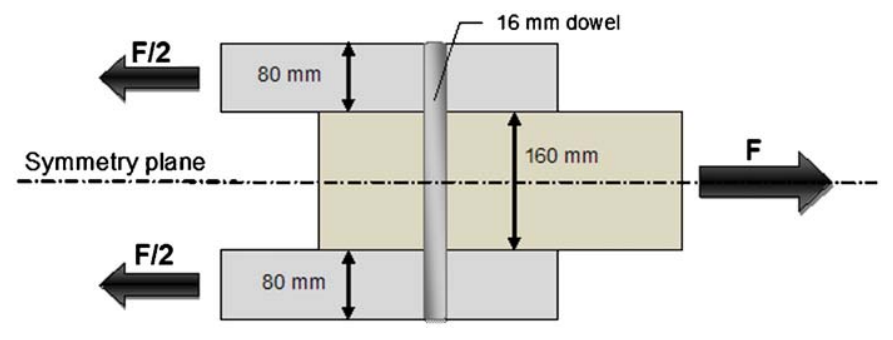

Fig. 15. Connection geometry.

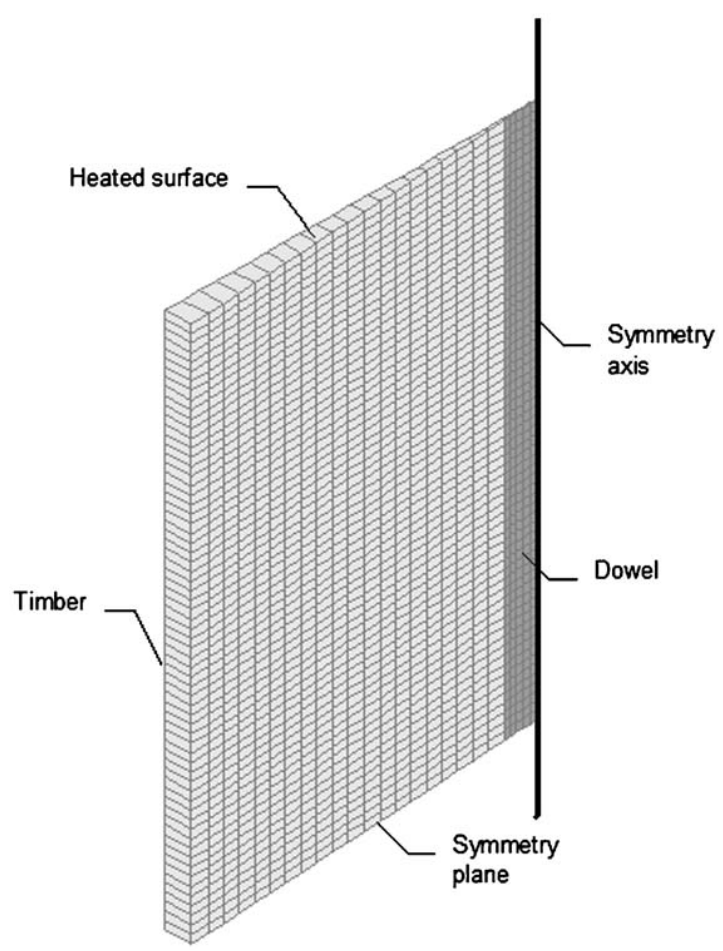

Fig. 16. Finite element mesh used for the thermal analysis.

experimental tests with $10 \mathrm{~mm}$ dowels and different side and central thickness and different angle of load to grain are presented. Table 2 summarises the different tests. Timber density was $456 \mathrm{~kg} / \mathrm{m}^{3}$ and the steel yield strength, considered with the nominal value, is $500 \mathrm{MPa}$. All other material properties were calculated using the default values presented previously in this paper. The finite element discretization used springs spaced at $2 \mathrm{~mm}$ with one beam element between each spring.

Comparison of numerical with experimental results is presented in Figs. 9-12. It can be observed that numerical results agree very well with experimental results either in terms of initial stiffness or ultimate strength, for parallel to the grain loading (cases S1 and S2) as for the case of the lateral member loaded perpendicular to the grain (cases S3 and S4). Here again, the ductility was somehow higher in the tests than in the model, especially for low values of the angle $\alpha$.

The behaviour of the model was also compared with Eurocode 5 and plastic theory (using the theoretical plastic moment for the fastener) failure loads and failure modes. Eurocode 5 is based in plastic theory but differs in the plastic moment for the dowel and on some empirical coefficients. It was observed that the obtained ultimate loads as well as the failure modes are in good agreement with EC5 and the results are shown in Table 3. In all cases, the differences between failure loads of the model at plastic failure loads are less than 5\%. Failure modes of numerical model are also in agreement with plastic theory and Eurocode 5.

\section{Description of the model at elevated temperatures}

The use of the component model for timber connections under fire loading is performed in a two-step approach: first, a threedimensional thermal analysis of the connection is carried out that allows the determination of the temperature field in fasteners and timber; second, the component model previously described for the connection is used to determine the mechanical behaviour of the connection.

The three-dimensional thermal analyses of the connections were carried out with material thermal properties defined in Eurocodes [23-25] using the program SAFIR. It is assumed that timber and steel will remain connected during thermal analysis and that no gap develops at the interface.

The finite element mesh used for the thermal analysis is different from the simple beam-spring finite element mesh used for the component model, which implies that temperatures in the dowel and in timber must be read from the thermal model and 

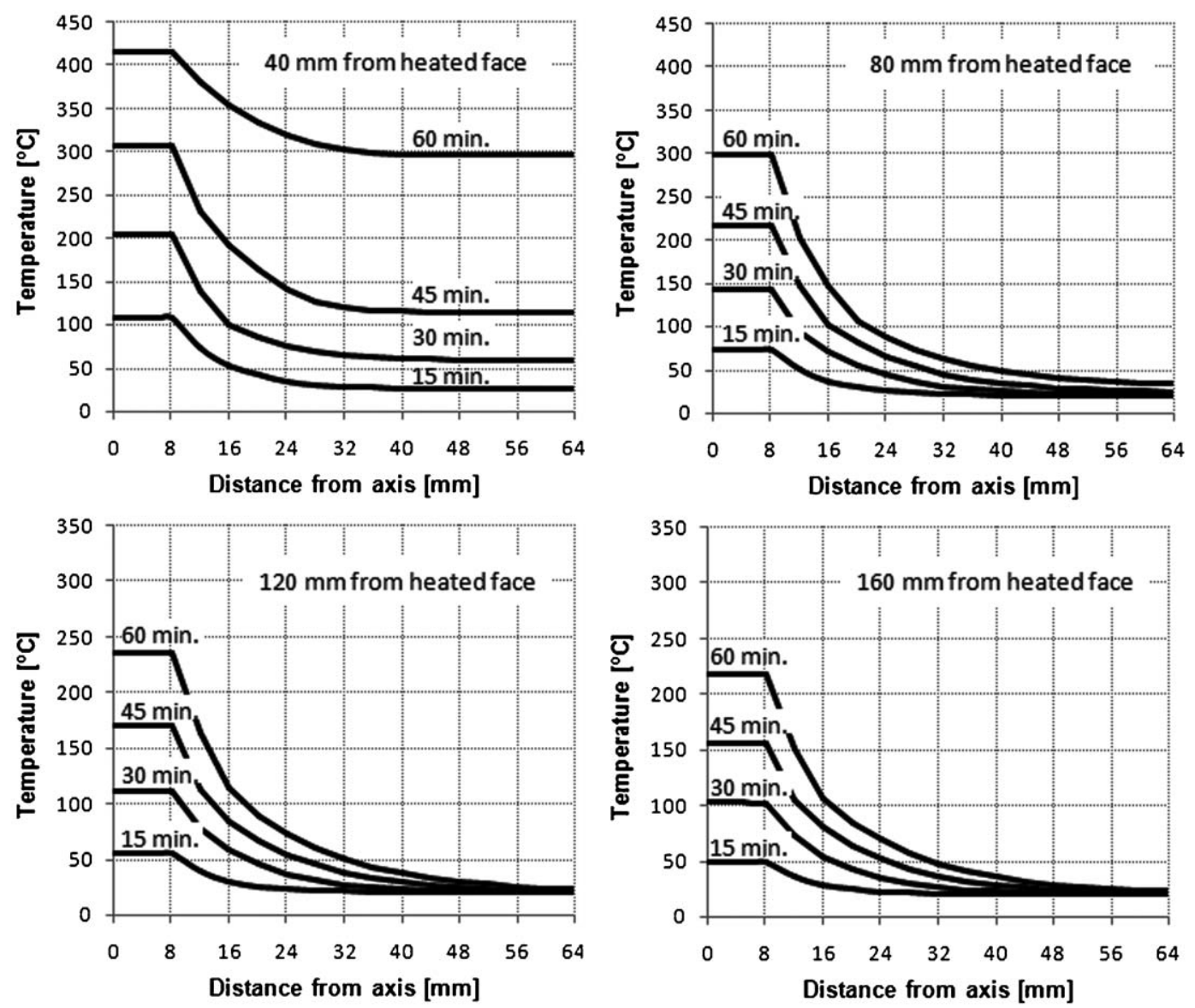

Fig. 17. Temperature profiles in lines perpendicular to fastener axis.
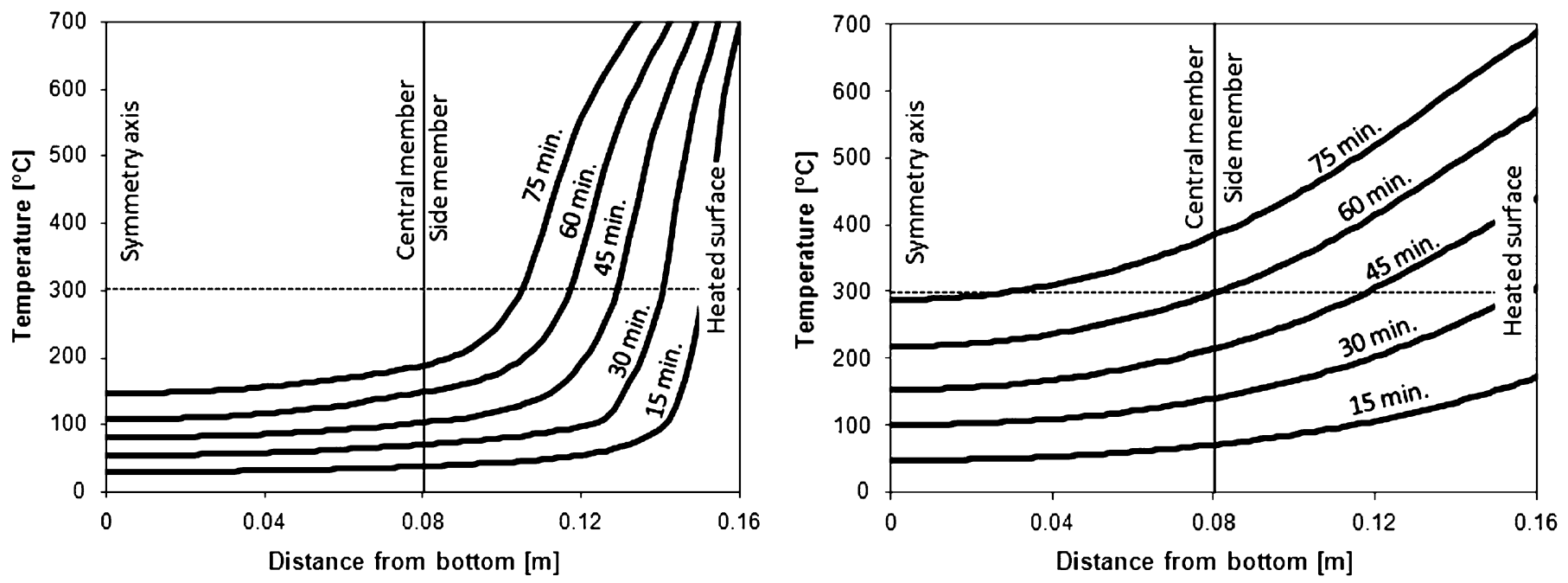

Fig. 18. Typical temperature distribution in timber parallel to the dowel at its interface with steel (left) and $8 \mathrm{~mm}$ apart (right).

converted to appropriate input temperatures for the mechanical component model.

The determination of the mechanical parameters for the timber component at elevated temperatures was based on Eurocode 5 reduced mechanical properties at elevated temperatures [25]. Since shear fasteners in timber connections work by compressing the timber, the reduction factors for compressive stiffness $\left(k_{E c}(\theta)\right)$ and strength $\left(k_{f c}(\theta)\right)$ defined in [25] were adopted for the timber component. The reduction factors are shown in
Fig. 13. By applying these factors for material properties described previously, the strength-displacement curves of the timber component at elevated temperatures can be obtained. The ultimate displacement was kept independent of temperature. Examples of these curves at selected temperatures are shown in Fig. 14.

The nonlinear mechanical properties at elevated temperature for the dowels are obtained from recommendations of Eurocode 3 [23]. 


\section{Model performance at elevated temperatures}

\subsection{Model behaviour}

The performance of the model is illustrated here for the case of single fastener (Fig. 15).

Thermal analysis was performed, using finite element program SAFIR, for an isolated fastener using a finite element mesh as shown in Fig. 16. Symmetry around the dowel axis was considered because it is assumed that temperature perturbations induced near the edges of the assembly will not influence the behaviour of

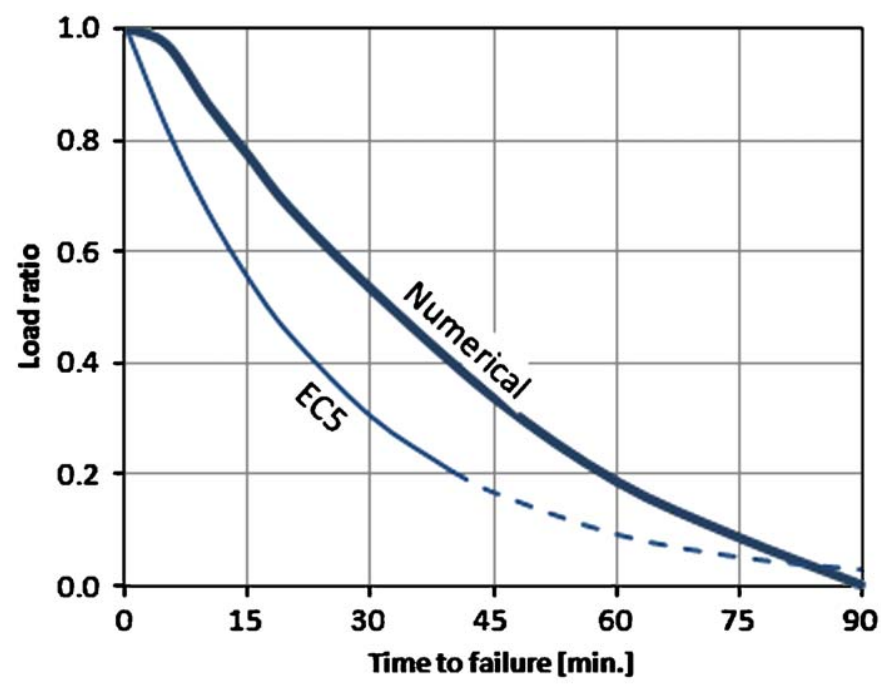

Fig. 19. Fire resistance for a single dowel connection. the connection, essentially dictated by phenomena that occur in the dowel or at the timber-dowel interface. The connection was heated only on the top surface and perfect thermal contact between timber and steel was assumed. As fasteners were in double shear, the represented mesh models only half the connection (bottom plane of the model is also a symmetry plane). Thermal properties for timber and steel were considered according to Eurocode 5 [25] and Eurocode 3 [23], respectively.

Timber density at $12 \%$ moisture content is $450 \mathrm{~kg} / \mathrm{m}^{3}$; moisture is $12 \%$. Accordingly, using Eqs. (3), (8) and (9) the embedding strength $F_{1,0}=F_{2,0}=495.9 \mathrm{~N} / \mathrm{mm}$, the yield displacement $d_{y, 0}=1.3 \mathrm{~mm}$ and the initial stiffness $K_{1,0}=369 \mathrm{~N} / \mathrm{mm}^{2}$. The ultimate displacement $d_{u, 0}$ was considered as $5.0 \mathrm{~mm}$. Steel yield strength for the dowel is $300 \mathrm{~N} / \mathrm{mm}^{2}$; the corresponding yield moment is $204800 \mathrm{~N} \mathrm{~mm}$.

Temperatures along the dowel axis used for the component model were taken at two different locations:

(a) for steel, temperatures are considered at the interface between the dowel and timber (temperatures are nearly uniform across the diameter of the dowel, see Fig. 17) and

(b) for timber, temperatures are taken at a distance $0.5 \mathrm{~d}$ from the dowel.

Some comments are needed regarding the choice of temperatures for timber at a distance $0.5 d$ from the dowel surface. The behaviour of the timber component model that represents the stiffness of timber will be strongly dependent on the temperature profile perpendicular to the dowel in timber. Since temperature in timber changes with the distance to the dowel, the spring can be regarded as a series of springs with different stiffness properties. As the model should remain simple, an equivalent, single, stiffness must be used for each timber component along the dowel (or equivalently a single temperature). It has been found by

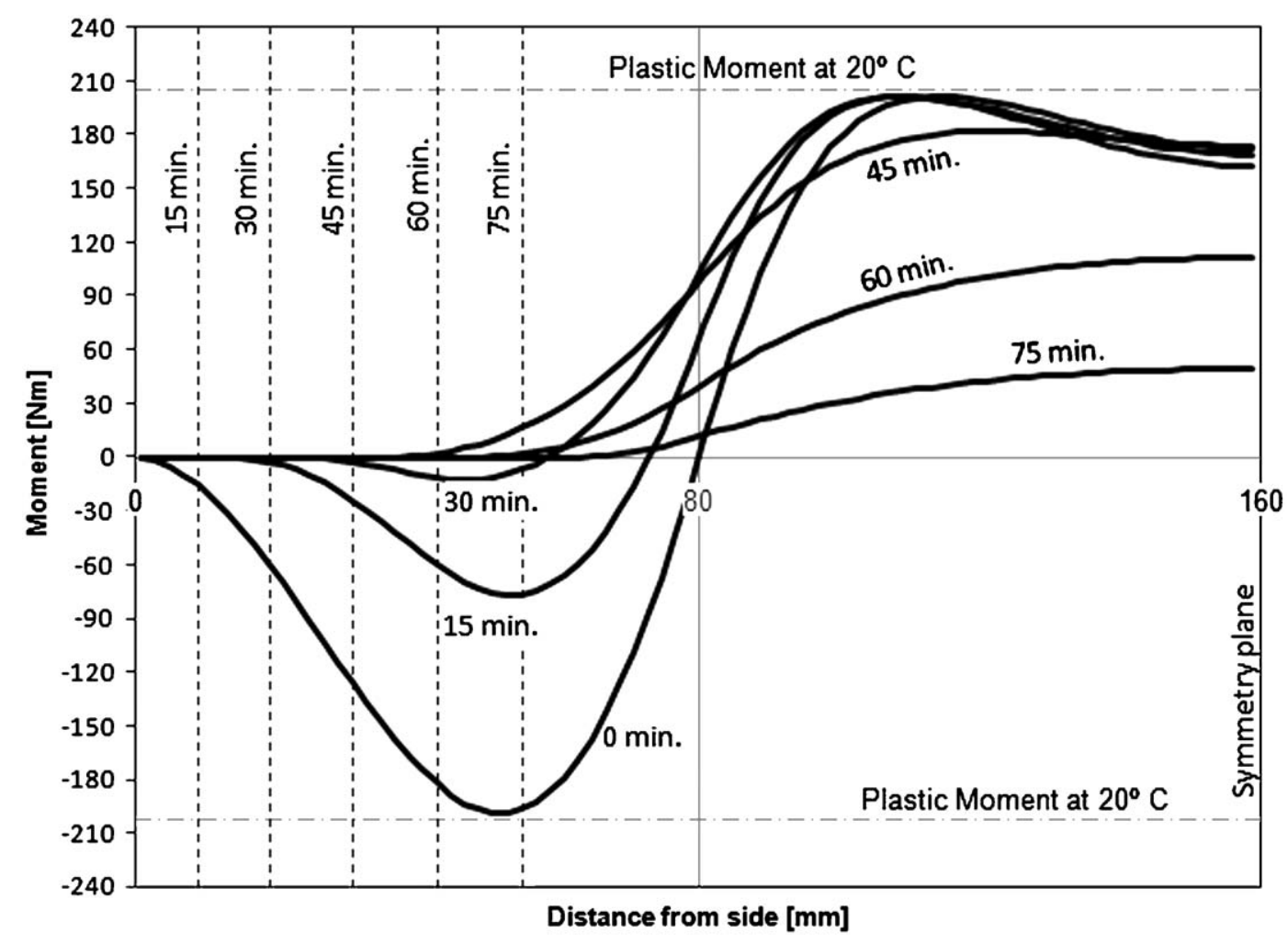

Fig. 20. Final moment diagrams in the dowel at times $0,15,30,45,60$ and $75 \mathrm{~min}$. 


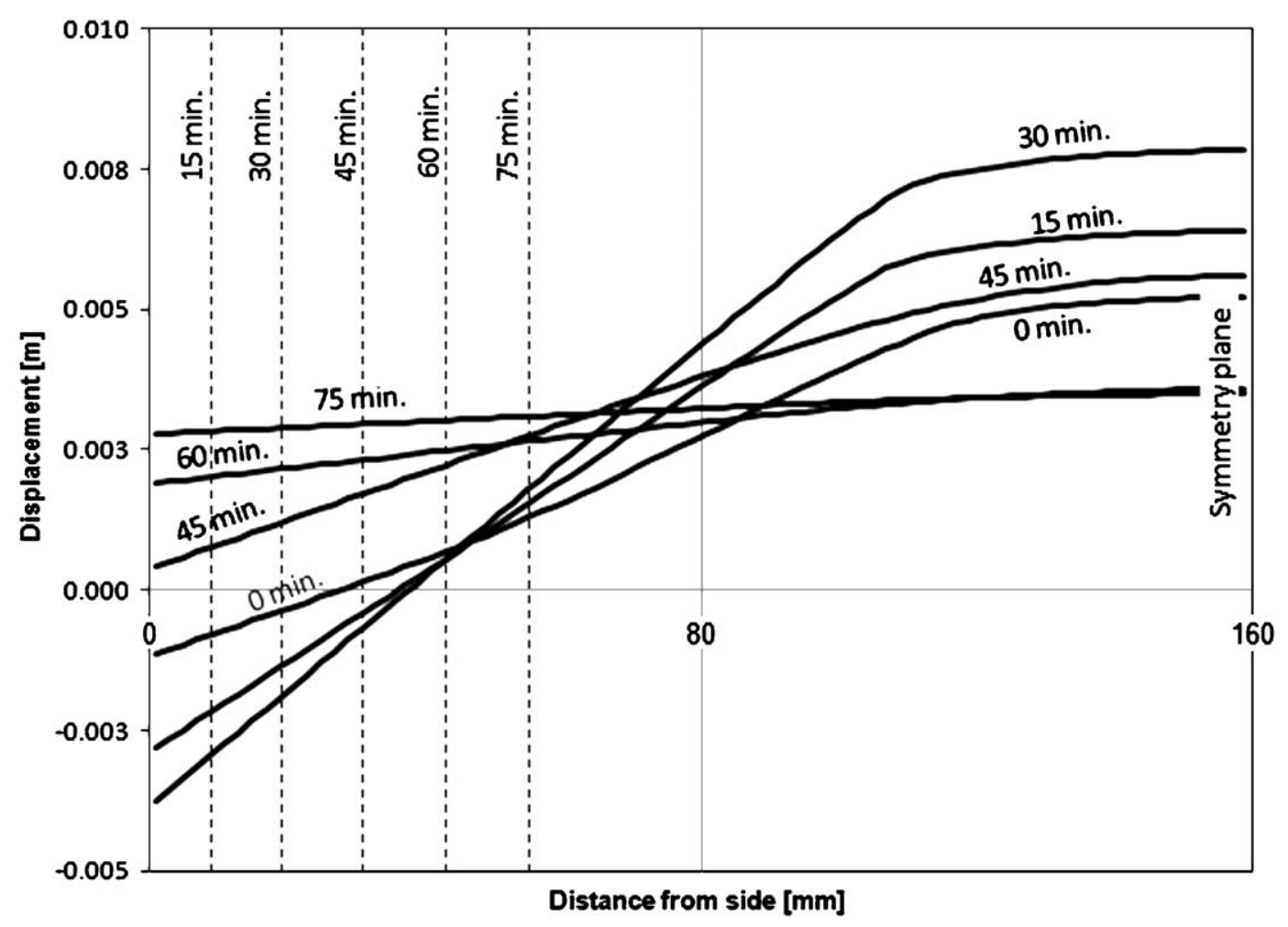

Fig. 21. Deformation of the dowel at failure at times $0,15,30,45,60$ and $75 \mathrm{~min}$.

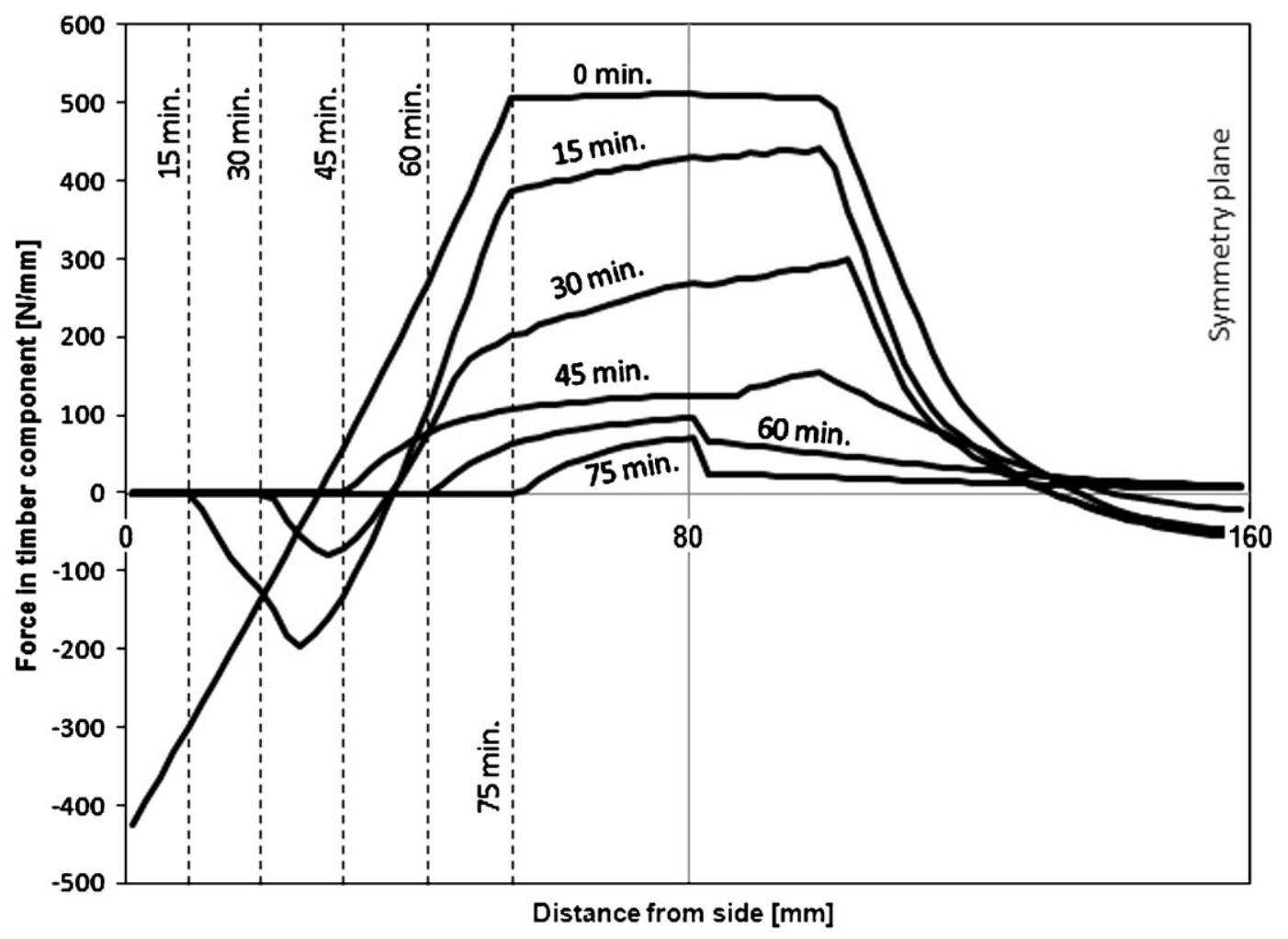

Fig. 22. Stresses at timber component at times $0,15,30,45,60$ and $75 \mathrm{~min}$.

calibration that the distance of half a diameter yields good correlations with the experimental results.

The distribution of temperatures in timber at the interface with the dowel and $8 \mathrm{~mm}$ away from the dowel are plotted in
Fig. 18. It is apparent that if the dowel/timber interface temperatures were used for calculation of the timber properties, it would be impossible for the connection to carry any load beyond $60 \mathrm{~min}$ (Fig. 18, left); however, this does not occur when 
temperatures are considered at $0.5 \mathrm{~d}$ from the dowel face (Fig. 18, right). Each of these temperature curves is then introduced in the component model and the material properties are adapted accordingly. Using the component model, load was here increasingly applied at a temperature distribution corresponding to a chosen time until failure of the connection (steady-state thermal situation). An ultimate load-time-to-failure curve can consequently be calculated.

The evolution of the time to failure with the load ratio is shown in Fig. 19. After an initial stage of about $5 \mathrm{~min}$ in which the load ratio remains almost unchanged, a steep reduction of the load ratio with time occurs. At $60 \mathrm{~min}$, the connection is still capable of sustaining $20 \%$ of its load-bearing capacity at time $t=0$ (this later value is calculated with unfactored material strength). For comparison purposes, Eurocode 5 [25] load ratio-time to failure curve is also shown (the dashed line indicates values beyond Eurocode 5 limit of $40 \mathrm{~min}$ ). It can be observed that numerical results yield longer times to failure than Eurocode 5 expression; however, as stated in [18], Eurocode 5 model is a conservative approximation, thus longer times to failure could be expected.

The connection was chosen so that all failure modes typical of timber connection in double shear could be observed: dowel with two plastic hinges; one hinge in the central element; and crushing of timber. The moment distribution along the dowel is plotted in Fig. 20. The vertical dotted lines shown in the figure indicate the limit of completely charred timber at certain time steps $\left(300^{\circ} \mathrm{C}\right)$; the vertical solid line represents transition between side and central member. It can be observed that failure mode for room temperature occurs with formation of two hinges in the fastener. As temperature increases, the maximum moment in the side member decreases and the failure mode changes to one hinge in the central element. As temperature continues to increase, and the effective thickness of the side member continues to decrease, the failure mode changes again, with a reduction of the bending

Table 4

Summary of experimental test results.

\begin{tabular}{|c|c|c|c|c|c|c|c|c|}
\hline \multirow[t]{2}{*}{ Author } & \multirow[t]{2}{*}{ Type } & \multirow[t]{2}{*}{ Series name } & \multicolumn{2}{|l|}{ Thickness } & \multirow{2}{*}{$\begin{array}{l}\text { Fastener } \\
\text { diameter }(\mathrm{mm})\end{array}$} & \multirow{2}{*}{$\begin{array}{l}\text { Number of } \\
\text { fasteners } \\
\text { (dowel+bolt) }\end{array}$} & \multirow{2}{*}{$\begin{array}{l}\text { Load } \\
\text { ratio (\%) }\end{array}$} & \multirow{2}{*}{$\begin{array}{l}\text { Time to } \\
\text { failure } \\
\text { (min) }\end{array}$} \\
\hline & & & Side $(\mathrm{mm})$ & Center (mm) & & & & \\
\hline \multirow[t]{2}{*}{ Laplanche et al. [26] } & Dowel & $16 \times 164$ & 84 & 160 & 16 & $6+2$ & $\begin{array}{r}29.9 \\
9.9\end{array}$ & $\begin{array}{l}54 \\
79\end{array}$ \\
\hline & Dowel & $16 \times 120$ & 64 & 112 & 16 & $6+2$ & $\begin{array}{r}30.1 \\
30.0 \\
20.0 \\
19.8 \\
9.7\end{array}$ & $\begin{array}{l}41 \\
38 \\
46 \\
45 \\
57\end{array}$ \\
\hline \multirow[t]{4}{*}{ Kruppa et al. [27] } & Dowel & $12 \times 90$ & 50 & 80 & 12 & $6+2$ & $\begin{array}{l}56.0 \\
28.0\end{array}$ & $\begin{array}{l}13 \\
32\end{array}$ \\
\hline & Dowel & $20 \times 110$ & 60 & 100 & 20 & $\begin{array}{r}6+2 \\
6+2 \\
12+4\end{array}$ & $\begin{array}{l}65.0 \\
33.0 \\
62.0 \\
31.0 \\
42.0 \\
21.0\end{array}$ & $\begin{array}{r}7 \\
35 \\
22 \\
41 \\
23 \\
38\end{array}$ \\
\hline & Bolt & $12 \times 90$ & 50 & 80 & 12 & $0+8$ & $\begin{array}{l}57.0 \\
24.0\end{array}$ & $\begin{array}{l}13 \\
22\end{array}$ \\
\hline & Bolt & $20 \times 110$ & 60 & 100 & 20 & $0+8$ & $\begin{array}{l}59.0 \\
30.0\end{array}$ & $\begin{array}{l}15 \\
24\end{array}$ \\
\hline
\end{tabular}

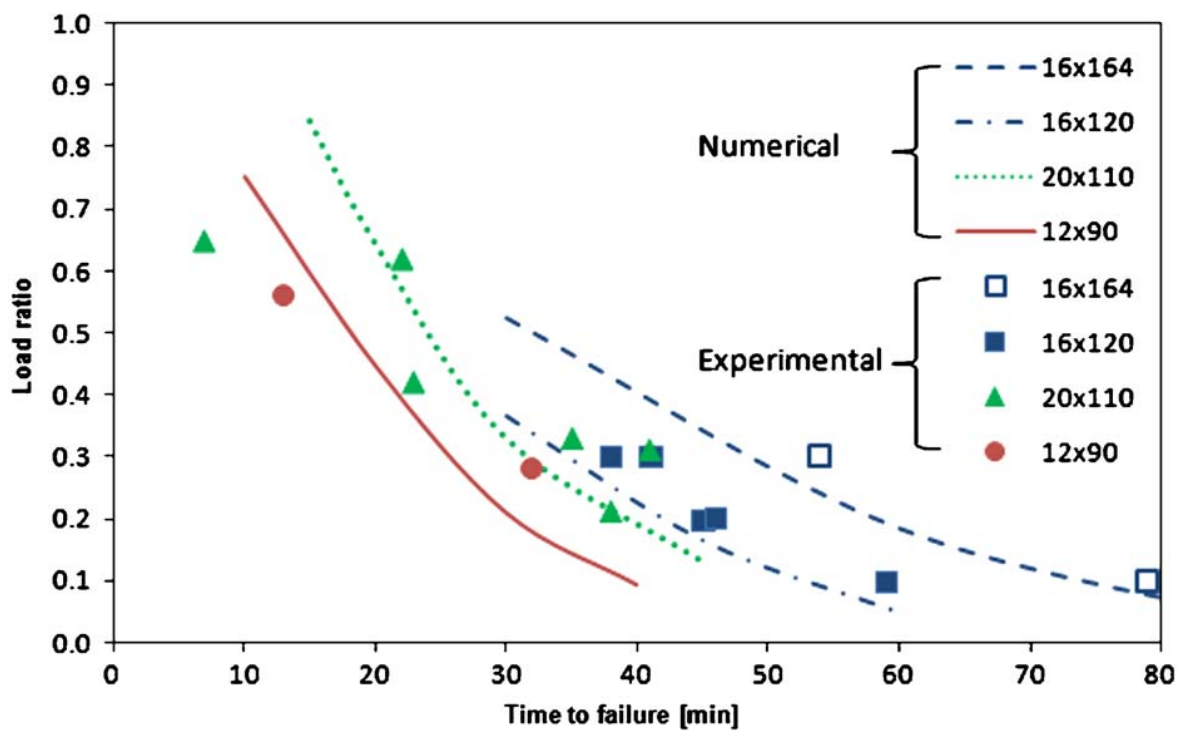

Fig. 23. Comparison between numerical and experimental results for dowels. 


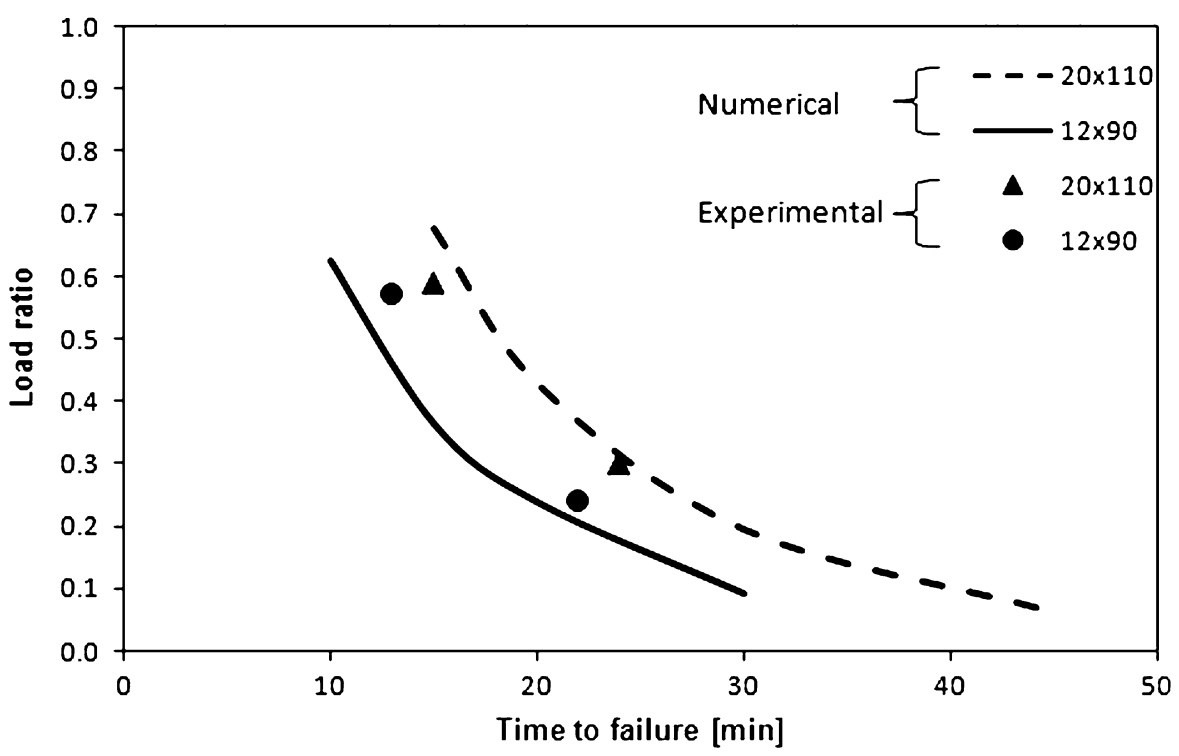

Fig. 24. Comparison between numerical and experimental results for bolts.

moment in the central member leading to failure controlled by crushing of timber without formation of plastic hinge.

In Fig. 21, dowel displacements at failure for times 0, 15, 30, 45, 60 and $75 \mathrm{~min}$ are plotted. Plastic hinge location can be clearly observed; in addition, as time increases, it is also observed that final displacements are controlled by failure of timber. Fig. 22 shows the stresses at the timber component for $0,15,30,45,60$ and $75 \mathrm{~min}$. It is interesting to note that compared with cold behaviour, after 15 or $30 \mathrm{~min}$ of fire exposure, the plateau corresponding to plastification of the timber component (approximately between 55 and $100 \mathrm{~mm}$ from exposed side) is no longer constant. This is because there is a reduction of strength for temperatures above $20^{\circ} \mathrm{C}$.

\subsection{Comparison with experimental results}

The model was assessed by comparing the numerical results with experimental tests with dowels and bolts. The results used for comparison purposes were those from Laplanche et al. [27] and Kruppa et al. [27]. Summary of side member thickness, fastener type, applied load level and time to failure are presented in Table 4. In dowelled connections, some of the dowels (usually one in four) were replaced by bolts to prevent separation of members during fire tests.

The methodology used for the analysis of fire resistance was as previously described: first a thermal analysis is performed and then the obtained temperatures are applied in the mechanical model. Numerical simulations were carried out using a single fastener because as stated in [18] the effect of the number of fasteners for the calculation of the load ratio-time-to-failure curves is very small.

Each test is represented by one point in Fig. 23 for dowelled connections and in Fig. 24 for bolts. It can be seen that a good agreement was found between the numerical and experimental results both for the case of dowels and bolts.

\section{Conclusions}

A component model for dowelled-type timber connections subjected to fire has been developed. Regardless of its simplicity it is quite capable of modelling the load-deformation behaviour of connections.

A generic constitutive model for the timber component can be defined with two parameters, namely the timber density and the dowel diameter. With available experimental embedding tests, it is possible to calibrate the constitutive model with more reliable information.

The component model showed good accuracy when used in several types of connections and compared with experimental results collected from different sources.

When applied to timber connections under fire loading, the component model showed interesting possibilities, allowing the identification and characterization of the main mechanisms of the connection behaviour.

\section{References}

[1] EN 1995-1-1:2004, Eurocode 5: Design of Timber Structures-Part 1-1: General-Common Rules and Rules for Buildings, CEN, Belgium.

[2] D.M. Moses, H.G.L. Prion, A three-dimensional model for bolted connections in wood, Can. J. Civ. Eng. 30 (3) (2003) 555-567.

[3] M. Patton-Mallory, F.W. Smith, P.J. Pellicane, Modeling bolted connections in wood: a three-dimensional finite-element approach, J. Test Eval. 26 (2) (1998) $115-124$.

[4] N. Kharouf, G. McClure, I. Smith, Elasto-plastic modeling of wood bolted connections, Comput. Struct. 81 (2003) 747-754

[5] K. Laplanche, Etude du comportement au feu des assemblages de structures bois: approche expérimentale et modélisation, $\mathrm{Ph}$. D. Dissertation, University Blaise Pascal (Clermont-Ferrand), France, 2006 (in French).

[6] L. Erdődi, I. Bódi, Experimental and numerical analysis of timber joints, in: C.A. Brebbia, W.P. de Wilde (Eds.), High Performance Structures and Materials II, WIT Press, Wessex, UK, 2004.

[7] C.J. Chen, T.L. Lee, D.S. Jeng, Finite element modeling for the mechanical behavior of dowel-type timber joints, Comput. Struct. 81 (2003) 2731-2738.

[8] M. Reid, J. Shin, P. Quenneville, Capacity predictions for one and two-row bolted timber connections, in: Eighth World Conference on Timber Engineering WCTE 2004, Lahti, Finland.

[9] P. Racher, J.F. Bocquet, Non-linear analysis of dowelled timber connections: a new approach for embedding modelling, Electron. J. Struct. Eng. 5 (2005) 1-9.

[10] K. Sawata, M. Yasumura, Estimation of yield and ultimate strengths of bolted timber joints by nonlinear analysis and yield theory, J. Wood Sci. 49 (2003) 383-391.

[11] N. Nishiyama, N. Ando, Analysis of load-slip characteristics of nailed wood joints: application of a two-dimensional geometric nonlinear analysis, J. Wood Sci. 49 (2003) 505-512.

[12] C.L.O. Santana, N.T. Mascia, Determination of fastener stiffness and application in the structural design with semi-rigid connections, in: Ninth World Conference on Timber Engineering, WCTE 2006, Portland, OR, USA.

[13] L. Jiang, Y.H. Chui, Finite element model for wood-based floors with lateral reinforcements, J. Struct. Eng._ASCE 130 (7) (2004) 1097-1107. 
[14] K. Hwang, K. Komatsu, Bearing properties of engineered wood products I: effects of dowel diameter and loading direction, J. Wood Sci. 48 (2002) 295-301.

[15] L.Y. Lam, Développement de modèles analytiques pour la prédiction du comportement élastique des assemblages mécaniques à broches dans la construction en bois, Ph.D. Dissertation, University of Liege, Belgium, 2006 (in French).

[16] L. Daudeville, L. Davenne, M. Yasumura, Prediction of the load carrying capacity of bolted timber joints, Wood Sci. Technol. 33 (1999) 15-29.

[17] C. Erchinger, A. Frangi, A. Mischler, Thermal investigations on multiple shear steel-to-timber connections, in: Ninth World Conference on Timber Engineering, WCTE 2006, Portland, OR, USA.

[18] J. König, M. Fontana, The Performance of Timber Connections in Fire-Test Results and Rules of Eurocode 5, in: S. Aicher, H.-W. Reinhardt (Eds.), Proceedings of the RILEM Symposium Joints in Timber Structures, Stuttgart, Germany, 2001, pp. 639-648.

[19] J.-M. Franssen, SAFIR. A thermal/structural program modelling structures under fire, Eng. J. AISC 42 (3) (2005) 143-158.
[20] EN 383:1993, Timber Structures. Test Methods. Determination of Embedment Strength and Foundation Values for Dowel Type Fasteners, CEN, Belgium.

[21] M.U. Pederson, Dowel Type Timber Connections-Strength Modelling, Ph.D. Dissertation, Rapport BYG DTU R-039, Technical University of Denmark, Denmark, 2002.

[22] K. Sawata, M. Yasumura, Determination of embedding strength of wood for dowel-type fasteners, J. Wood Sci. 48 (2002) 138-146.

[23] EN 1993-1-2: 2005, Eurocode 3: Design of Steel Structures-Part 1-2: General Rules-Structural Fire Design.

[24] EN 1991-1-2:2002, Eurocode 1: Actions on Structures-Part 1-2: General Actions-Actions on Structures Exposed to Fire, CEN, 2002.

[25] EN 1995-1-2:2004, Eurocode 5: Design of Timber Structures-Part 1-2: General-Structural Fire Design. CEN, 2004.

[26] K. Laplanche, D. Dhima, P. Racher, 2004. Predicting the behaviour of dowelled connections in fire: fire test results and heat transfer modelling, in: Eighth World Conference on Timber Engineering, WCTE 2004, Lahti, Finland.

[27] J. Kruppa, T. Lamadon, P. Racher, 2000. Fire resistance tests of timber connections, CTICM, INC-00/187-JK/NB. 